Didaktik : Jurnal Pendidikan Guru Sekolah Dasar, ISSN : 24775673

Sekolah Tinggi Keguruan dan IImu Pendidikan Subang

Volume IV Nomor 2, Desember 2018

\title{
SASTRA KULINER SEBAGAI SARANA PENDIDIKAN KARAKTER (ANALISIS NOVEL GERIMIS DI ARC DE TRIOMPHE KARYA NUNIK UTAMI)
}

\author{
R. Suparman Mustapa ${ }^{1}$, Haris Supratno ${ }^{2}$ \\ 1,2Pascasarjana Universitas Negeri Surabaya \\ 1'radensaasa123@gmail.com
}

\begin{abstract}
Culinary literature is often associated with cooking or cooking, even though there is an implicit meaning from every literature. There is advice contained in stories about food or food. The K13 curriculum that is being applied in Indonesia is referred to as a character education based curriculum. The application of character education requires a more attractive means for students to be interested, including using culinary literature. The Drizzle Novel in the Arc De Triomphe by Nunik Utami contains stories about foods that contain moral messages. The goodness found in the Gerimis novel in the Arc De Triomphe of Nunik Utami's work is honesty, help, and responsibility wrapped in stories about culinary. The approach used in this study is a qualitative descriptive approach. The data source in this study is Drizzle in the Nunik Utami Arc De Triomphe. The process of collecting data uses the method of reading, and taking notes. After the collected data is then analyzed using content analysis. The results of the study explained that the Gerimis novel in the Arc De Triomphe of Nunik Utami's work could be used as a means of developing character education in schools.
\end{abstract}

Keywords: Culinary Literature, Character Education, and Drizzle Novel in Arc De Triomphe

\begin{abstract}
ABSTRAK
Sastra kuliner sering dihubungkan dengan tata boga atau masakan, padahal ada makna tersirat dari setiap sastra. Ada nasihat yang terkandung dalam cerita tentang kuliner atau makanan. Kurikulum K13 yang sedang diterapkan di Indonesia disebut sebagai kurikulum berbasis pendidikan karakter. Penerapan pendidikan karakter membutuhkan sarana yang lebih menarik agar siswa tertarik, di antaranya dengan menggunakan sastra kuliner. Novel Gerimis di Arc De Triomphe Karya Nunik Utami berisi cerita tentang makanan yang mengandung pesan moral. Kebaikan yang terdapat dalam novel Gerimis di Arc De Triomphe Karya Nunik Utami berupa kejujuran, tolong-menolong, dan tanggung jawab yang dibalut dengan cerita tentang kuliner. Pendekatan yang digunakan dalam penelitian ini adalah pendekatan deskriptif kualitatif. Sumber data dalam penelitian ini adalah Gerimis di Arc De Triomphe Karya Nunik Utami. Proses pengumpulan data menggunakan metode membaca, dan mencatat. Setelah data terkumpul kemudian
\end{abstract}


dianalisis menggunakan analisis isi. Hasil penelitian menjelaskan bahwa novel Gerimis di Arc De Triomphe Karya Nunik Utami dapat digunakan sebagai sarana mengembangkan pendidikan karakter di sekolah.

Kata Kunci: Sastra Kuliner, Pendidikan Karakter, dan Novel Gerimis di Arc De Triomphe

\section{A. Pendahuluan}

Penulisan karya sastra pada era saat ini semakin mendunia sehingga memberikan kesempatan yang baik bagi pengarang untuk dapat mengekspresikan hal yang sering terabaikan namun berperan penting bagi kehidupan. Dalam hal ini berkaitan dengan sastra kuliner. Karya sastra merupakan karya manusia yang dihasilkan dari pemikiran dengan imajinasi tinggi, sehingga dapat melahirkan ciptaan yang berestetika tinggi dan dapat membuat pembaca merasakan feel dari karya tersebut. Karya sastra diciptakan oleh pengarang untuk dinikmati agar bisa bermanfaat di masyarakat dan dalam kehidupan.

Pengarang tidak berhenti melakukan imajinasi atau khayalan untuk menghasilkan sesuatu yang baru, karena karya sastra mengandung keindahan dari segi penyajian bahasa, perjalanan cerita, dan manfaat yang berupa pengetahuan dan wawasan bagi pembaca. Karya sastra sebagai salah satu unsur budaya, memiliki aneka ragam jenis. Jenis-jenis karya sastra tersebut antara lain berupa karya sastra tulis modern seperti novel, cerpen, drama dan puisi. Novel merupakan salah satu jenis karya sastra Indonesia yang paling menarik, mampu merefleksikan berbagai fenomena yang terjadi di masyarakat (Supratno, 2016:1).

Era saat ini novel merupakan karya sastra yang banyak diminati oleh hampir semua kalangan, terutama para generasi muda. Hal ini disebabkan karena bahasa, pesan, dan cerita di dalam novel mengandung kesan tertentu. Kesan yang terdapat dalam sebuah novel sampai kepada pembaca seolah-olah terlibat langsung pada cerita tersebut. Pengarang menciptakan sebuah karangan dengan tujuan tertentu, di antaranya pengorbanan, 
penindasan, perjalanan hidup, cerita inspiratif, perjalanan kasih sayang dan lain sebagainya. Berbeda dengan karya sastra dalam novel Gerimis di Arc de Triompe karya Nunik Utami, karya tersebut menggambarkan keajaiban dalam makanan. Keajaiban disini bukan keajaiban yang bersifat khayalan dan imajinatif belaka melainkan suatu keajaiban yang bersifat nyata sehingga dapat mengubah cara pandang seseorang terhadap makanan.

Penikmat kuliner secara umum hanya tertarik pada segi tata boga atau disebut gastronomi dan berujung pada komersialisasi. Ada yang memandang kuliner hanya sebagai tujuan dari kehidupan mereka, namun kuliner yang diperkenalkan dalam novel Gerimis di Arc de Triompe karya Nunik Utami tidak sebatas berakhir pada komersialisasi tetapi bagaimana strategi menikmati dan dirasakan lebih mendalam sehingga mampu memunculkan nilai-nilai filosofi kehidupan yang lebih indah. Sebagian kalangan masyarakat

umum mengungkapkan bahwa suatu makanan tidak mempunya kaitan dengan memori maupun sejarah kehidupan seseorang. Namun, ketika seseorang menikmati atau mencicipi suatu makanan terdapat sebuah proses autobiografi yang dikonsumsi oleh penikmat makanan.

Menurut Halligan (2004:11), makanan memiliki hubungan tematik dengan tempat dan keinginan untuk memberitahukan pembaca layaknya bicara dengan makanan. Makanan adalah bagian yang esensial bagi keberadaannya, makanan yang dimakan dan kenangan memiliki autubiografi. Gerimis di Arc de Triomphe Karya Nunik Utami merupakan karya sastra yang menceritakan mengenai kuliner, akan tetapi tidak hanya berkaitan dalam hal fisikal dan material, sebagaimana yang digambarkan para tokoh di dalam novel yaitu merasakan, mengonsumsi dan menikmati suatu makanan, akan tetapi juga bersifat sosial kultural.

Menguraikan kenikmatan dalam makanan yang meskipun memuaskan rasa lapar adalah 


\begin{tabular}{|c|c|}
\hline 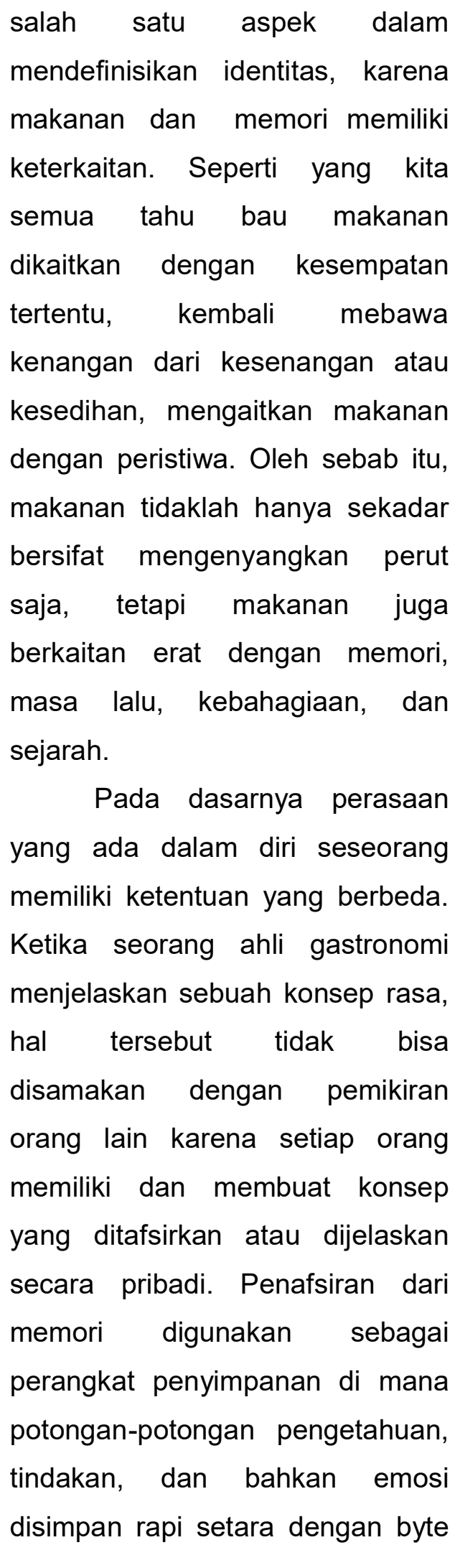 & 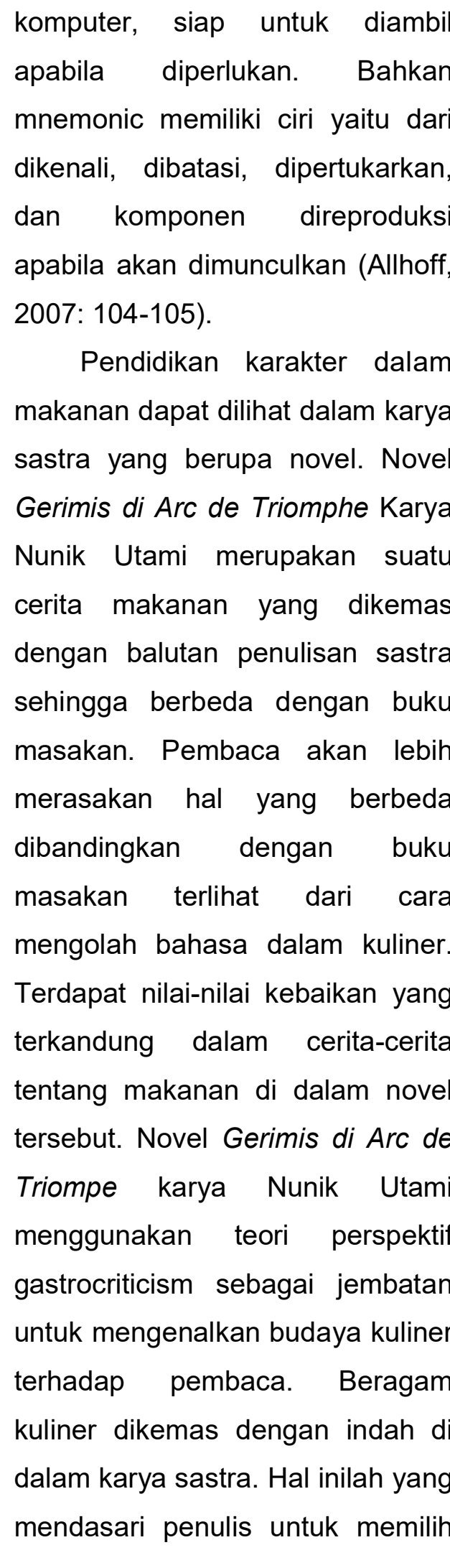 \\
\hline
\end{tabular}


novel Gerimis di Arc de Triompe karya Nunik Utami sebagai bahan objek dalam penelitian dengan menggunakan kajian gastrocriticism.

\section{B. Landasan Teori}

Gastrocriticism

diperkenalkan oleh Ronald Tobin merupakan etika seseorang dalam menghargai suatu makanan. Pada pelajaran gastronomi Ronald Tobin, orang dapat melihat bagaimana cara mencari etika metafora gastronomis yang dikonsep dalam literatur untuk menemukan bahwa pada akhirnya daging telah menjadi kata yang memiliki bahasa tubuh dalam wacana sastra (Tobin, 1990: 3).Simbol, mimpi, mitos, bahkan tanda-tanda dari segala jenis mampu melihat keterkaitan antara memasak dan sastra. Makanan merupakan paradigmatik tindakan sastra, yaitu berminpi atau menghayal untuk mengenal diri sendiri. Gastronomi sendiri dapat dianggap sebagai kreatif penampilan. Maka dari pandangan tersebut, gastro-kritik berfungsi sebagai latar belakang dari kedua seni yang berhubungan dengan pengungkapan pengarang, sedangkan memasak sebagai pencipta tertinggi metamorfosis.

Sampai pada saat ini umumnya masyarakat mengatahui bahwa tataboga dan karya sastra merupakan dua ilmu pengatahuan yang berbeda. Tataboga merupakan bagian yang bertujuan untuk mengurusi kenikmatan mulut dan perut, sedangkan dunia fiksi merupakan seni atau karya sastra, rasa dan jiwa. Oleh sebab itu, tataboga ditempatkan dalam bagian gastronomi, dan dunia fiksi ditempatkan dalam bagian teori sastra. Dengan demikian, keduanya membuat sesuatu yang baru dari sesuatu yang ada melalui proses seleksi, dan imajinasi karena mereka melakukan pola dasar, suci, dan bertindak kreatif yang menghasilkan kemurnian, hasil yang kompleks yang mengubah penikmat secara emosional, intelektual, dan fisik (Tobin, 1990: 4). Gastrocriticism juga yang dikemukakan oleh Marion Halligan adalah suatu terobosan baru yang bertujuan untuk melihat 
keterkaitan antara sastra dan kuliner. Marion Halligan menulis tiga buku yang berjudul Eat My Word, Cockles of the heart, dan The Taste of Memory. Ketiga buku tersebut berbicara tentang makanan, karena untuk mengkaji itu Halligan menggunakan kajian gastrocriticism Ronald Tobin untuk mengatahui kaitan antara sastra dan kuliner.

Salah satu dari buku Halligan Eat My Word menceritakan bahwa orang makan hanya untuk kelangsungan kehidupan, ketika mereka tidak tahu bagaimana hidup untuk makan. Sehingga dapat digaris bawahi pentingnya makanan secara budaya dan sejarah. Seorang koki yang hanya mata pencariannya adalah membuat makanan lain yaitu membuat makanan yang dimulai dari pikiran, maka ada ungkapan yaitu makanan untuk berfikir, dari ungkapan tersebut memiliki banyak makna. Tidak hanya mengacu terhadap makanan nyata, tetapi juga memiliki simbolis. Dari makanan seseorang dapat tahu banyak dari apa yang dibeli, siapa yang memakannya, dan siapa yang memasaknya. Gastrocriticism secara garis besar yaitu mengenai etika seseorang dalam menghargai suatu makanan. Pada studi gastronomi orang dapat melihat bagaimana cara mencari etika metafora gastronomis yang dikodekan dalam literature (Tobin, 1990:3).

Makanan merupakan aspek penting dari literatur apa pun, terutama dalam novel, di mana Halligan memandang hal itu penting untuk pengalaman karya seni. Dimana makanan memiliki peran yang menggambarkan karakteristik spesifik dari seorang individu. Seperti cerita madu dan pooh merupakan karya sastra yang ceritanya mengenai makanan. Cerita pendek "Malcolm" menggambarkan makanan sebagai kerangka struktural dalam ceritanya. Dalam cerita Malcolm dimana suami Bertha digambarkan sebagai sosok tokoh yang memiliki sifat penuh kasih "untuk berbicara tentang makanan dan untuk memuliakan". Oleh sebab itu, salah satu cara untuk memandang perlakuan tokoh tersebut terhadap makanan menggunakan perspektif 
gastrocriticism untuk membahas karya tersebut.

Perspektif gastrocriticism di dalam karya sastra berupa novel muncul karena adanya pengaruh antara ilmu antropologi sastra dan sosiologi sastra. Kajian antropologi sastra memberikan penilaian bahwa makanan turut ikut serta memperkaya wawasan karya sastra khususnya dalam bidang kuliner. Kajian sosiologi sastra mengarah kepada masyarakat yang memiliki budaya kuliner. Makanan khas yang terdapat di setiap kota menjadi ciri kota tersebut.

Novel Gerimis di Arc de Triomphe Karya Nunik Utami menggambarkan suatu perjalanan kehidupan disertai kekayaan kuliner. Dalam mengkaji novel ini dimana cerita, kesan mengenai makanan yang terdapat dalam novel, maka penulis menggunakan perspektif gastrocritisicm yang diperkenalkan oleh Halligan yaitu tiga konsep diantaranya konsep makanan dan kesenangan, makanan dan seni, makanan dan sejarah untuk membahas kedua novel tersebut.

\section{Metode Penelitian}

Penelitian ini menggunakan pendekatan deskriptif kualitatif. Sumber data dalam penelitian ini adalah Gerimis di Arc De Triomphe Karya Nunik Utami. Proses pengumpulan data menggunakan metode membaca, dan mencatat. Setelah data terkumpul kemudian dianalisis menggunakan analisis isi.

\section{Hasil dan Pembahasan}

\section{Refleksi Kejujuran dalam Kuliner}

Novel Gerimis di Arc De Triomphe karya Nunik Utami menceritakan mengenai makanan dalam novelnya yang mengandung pesan moral. Kebaikan yang terdapat dalam novel Gerimis di Arc De Triomphe Karya Nunik Utami berupa kejujuran. Hal tersebut dapat lihat pada kutipan dibawah ini:

Bunga mengangguk. "Ngerti, kok. Sup bawang bombai." Bunga tak henti-henti menatap Darel. Gadis itu sangat bersyukur bisa melihatnya dari dekat lagi. Selama Darel 
Didaktik : Jurnal Pendidikan Guru Sekolah Dasar, ISSN : 24775673

Sekolah Tinggi Keguruan dan IImu Pendidikan Subang

Volume IV Nomor 2, Desember 2018

tinggal di Prancis, Bunga hanya mengobati rindunya dengan melihat acara kuliner yang dipandu oleh Darel di TV. Saat itu juga, Bunga tahu, Darel bukan Darel yang dulu lagi. Dia sudah menjadi milik semua orang. "Lucu, ya. Gue nggak pernah menyangka kita akan bertemu di sini. Gimana kegiatan lo, Rel?" Odetta melempar senyum (Nunik Utami, 2013:31).

Kutipan di atas menjelaskan Bunga sangat merindukan Darel. Bunga sangat bersyukur kini bisa bertemu kembali dengan temannya itu yang membuat hati Bunga kagum dan ingin menemani keman pun Darel pergi bahkan sampai berkeinginan membangun toko bersama darel.

Kejujuran bunga dan kesetiaannya setiap acara kuliner yang dipandu oleh Darel di televise tidak pernah terlewatkan. Menjadi seorang asisten Chef Aldric di Le Culinairi tidak gampang, tapi dengan prestasi Darel yang sangat mumpuni akhirnya terpilih menjadi asisten chef di Culinairi tersebut. Murid mana yang tidak suka di bimbing oleh seorang Chef yang pintar dan juga memiliki rupa yang menawan.
Tentunya seorang murid merasa tertarik belajar ketika yang mengajarkan gurunya tingkat dunia dan asisten chef terkenal dari Indonesia, ketidak sabaran Bunga tidak tertahankan lagi segera cepat-cepat masuk ke dalam kelas untuk bertemu chef tersebut. demikian dapat kita lihat pada kutipan berikut:

"Rindu pun terbang. Satu hal yang tidak disadari oleh Darel. Ada sesuatu yang meletupletup di hati Bunga. Mata gadis itu tak lepas-lepas dari wajah Darel. Bunga begitu menikmati suasana. Dia merasa Darel akan mampu membuatnya menjadi bintang di dapur. Keinginannya untuk membuat gerai roti semakin tertancap di hati yang paling dalam." (Nunik Utami, 2013:39).

Data di atas menjelaskan ketika Bunga sudah tidak sabar ingin cepat ketemu Darel dan langsung diajarkan oleh asisten chef terkenal itu. Ketidak sabaran pengin cepat-cepat masuk ke dapur untuk membuat gerai roti semakin tertancap di hati Bunga yang paling dalam. Rasa kejujuran ingin bertemu Darel dan rasa ingin memiliki seorang chef yang sangat terkenal semakin meluap dalam hati Bunga. 
Didaktik : Jurnal Pendidikan Guru Sekolah Dasar, ISSN : 24775673

Sekolah Tinggi Keguruan dan IImu Pendidikan Subang

Volume IV Nomor 2, Desember 2018

2. Refleksi Tolong-menolong dalam Kuliner

Novel Gerimis di Arc De

Triomphe karya Nunik Utami menceritakan mengenai makanan, dalam novel tersebut mengandung pesan-pesan moral. Kebaikan yang terdapat dalam novel Gerimis di Arc De Triomphe Karya Nunik Utami berupa tolongmenolong. Ketika Bunga sedang menikmati hidangan sup yang dipesannya membuat Bunga mengacungkan jempol yang rasanya tidak seperti sup yang biasa di konsumsinya. Hal tersebut dapat lihat pada kutipan dibawah ini:

"kalau lo mau, gue bisa ngajarin bikin sup ini. Gampang, kok. Cuma bawang bombai diiris tipis-tiis, dicampur dengan kuah kaldu sapi. Dulu sup ini dicitakan oleh raja Louis XV. Menu yang kayak gini, sih, gue sudah di luar kepala. Udah lewat jauh," Darel menjetikkan jarinya. (Nunik Utami, 2013:41).

Pada data di atas
menjelaskan Bunga setelah
mengkonsumsi makanan yang
dipesan berupa sup khas Prancis
itu segera cepat-cepat pulang ke
apartemennya dan ingin membuat

sup seperti yang baru Bunga nikmati bersama Darel.

Darel disini menawarkan keada temannya itu untuk membuatkan sekaligus mengajarkan bagaimana strategi pembuatan soup, dan cara pemilihan bahan-bahan yang menjadikan hidangan soup tersebut mempunyai cita rasa yang mampu menarik para pecinta kuliner, dalam membuat French Onion Soup yang menjadi hidangan makanan kesukaan masyarakat Prancis itu. Selain cara pemilihan bahan-bahan, untuk membuat soup chef Aldric juga memberikan strategi supaya anak didiknya cepet menangkap, menerima dari hasil apa yang diberikannya. Hal itu dapat kita lihat dibawah ini:

"Satu hal yang perlu kalian ketahui. "Chef Aldric mengangkat kepalanya, memandangi seluruh muridnya. Wortel yang tampak segar itu terjepit di antara jari tangan Chef Aldric yang subursubur. Sementara, pisau ditangan kanannya mengayunayun ketika dia berbicara.

"Selain pemilihan bahan yang baik, cara mengelola yang benar, penggunaan peralatan yang tepat, keberhasilan dalam menyediakan masakan khas Prancis adalah urutan penyajian 


saat menghidangkan makanan
tersebut." (Nunik Utami,
2013:58).
Berdasarkan data di atas
yang menjelaskan seorang guru
chef Aldric sedang memberikan
kuliah mengenai strategi
memotong wortel yang harus
sama rata dalam memotongnya.
Karena hidangan Prancis sangat
memperhatikan dalam
menyiapkan makanan sekecil
apapun. Juga cara pemilihan
bahan-bahan yang bagus dan
baik.

\section{Refleksi Tanggung Jawab dalam Kuliner}

Novel Gerimis di Arc De Triomphe karya Nunik Utami menceritakan mengenai makanan, dalam novel tersebut mengandung pesan-pesan moral. Kebaikan yang terdapat dalam novel Gerimis di Arc De Triomphe Karya Nunik Utami berupa tanggung jawab.

Berangkat dari kencan pertamanya Bunga dengan Darel, membuat Bunga sangat kebingungan dalam mencari baju yang cocok untuk kencan bersama lelaki yang selama ini menjadi impian. Akan tetapi setelah Bunga sampai di sebuah restoran dimana mereka berdua ingin menikmati hidangan masakan bersama semua diluar dugaan, hanya penyesalan yang diterima oleh Bunga dimana Darel yang tidak kunjung datang. Hal ini dapat kita bisa lihat dalam kutipan dibawah ini:

"Aduuh! Kenapa ponselnya mati, sih?" Bunga memijit keningnya. Juga lehernya yang tak henti-henti melongok ke pintu masuk, kalau-kalau kepala dengan duri landak itu muncul. Bunga mengambil spagetinya dengan garpu. Saus béchamel semakin mengental bercampur spageti karena makanan itu sudah dingin. Dilahapnya makanan itu sedikit. Lalu, tangan Bunga mengaduk-aduk saus krim kental itu hanya untuk mengusir gundahnya (Nunik Utami, 2013:119).

Data di atas menggambarkan kekecewaan Bunga disaat kencan pertamanya bersama Darel tidak sesuai dengan yang diharapkan Bunga. Darel meskipun memiliki kemampuan dalam kuliner bahkan menjadi asisten chef dunia itu mempunyai kebiasaan yaitu sering lupa. Akan tetapi meskipun darel memiliki kebiasaan lupa kambuh, 
Didaktik : Jurnal Pendidikan Guru Sekolah Dasar, ISSN : 24775673

Sekolah Tinggi Keguruan dan IImu Pendidikan Subang

Volume IV Nomor 2, Desember 2018

tetapi asisten chef itu bertanggung

jawab atas perbuatannya yang

sudah membuat Bunga merasa

kecewa dengan janjinya. Untuk

menebus kesalahan Darel kembali

mengajak Bunga untuk menemani

jalan-jalan supaya Bunga tidak

sumpek sendirian di

apartemennya. Hal itu dapat kita

lihat dalam kutipan berikut:

"Uda, ah. Nggak usa pakai ngambek begitu. Norak. Lo piker gue nggak sumpek banget karena kebanyakan kerjaan?" Darel berusaha membujuk Bunga.

Bunga masih diam.

"Temani gue jalan-jalan, yuk!" suara darel memenuhi rongga telinga Bunga.

Pada cuplikan tersebut dapat kita lihat bahwa Darel mengakui kesalahannya kepada Bunga. Karena kebanyakan kerjaan dan juga kebiasaan lupanya yang sering terjadi, maka Darel mengajak Bunga kembali untuk menemaninya jalan-jalan supaya tidak sumpek di kamar terus. Sekaligus menebus kesalahan yang telah diperbuat.

\section{E. Kesimpulan}

Kurikulum K13 yang diterapkan di Indonesia disebut sebagai kurikulum berbasis pendidikan karakter. Penerapan pendidikan karakter membutuhkan sarana yang lebih menarik agar siswa tertarik, di antaranya dengan menggunakan sastra kuliner.

Novel Gerimis di Arc De Triomphe Karya Nunik Utami berisi cerita tentang makanan yang mengandung pesan moral. Kebaikan yang terdapat dalam novel Gerimis di Arc De Triomphe Karya Nunik Utami berupa kejujuran, tolong-menolong, dan tanggung jawab yang dibalut dengan cerita tentang kuliner.

Sastra kuliner tidak hanya
sebagai pengenyang dan
kepuasan perut saja melainkan
sastra kuliner disini sebagai sarana
pendidikan karakter.

\section{DAFTAR PUSTAKA}

Allhoff, Fritz dan Dave Monroe (Ed.). 2007. Food and Philosophy Eat, Think, and Be Merry. Australia: Blackwell.

Halligan, Marion. 1990. Eat My Words. North Ryde: Angus \& Roberston 
1996. Cockles of the

Heart . Melbourne: Reed Books. . 2004. The Memory of

Taste. Australia. Alexander

Street.

Mareta, Dwi Artika. 2016. Novel

Aruna dan Lidahnya Karya

Laksmi Pamuntjak Perspektif

Gastrocriticism. FBS Surabaya.

Nunik, Utami. 2013. Gerimis di Arc

de Triomphe. Yogyakarta:

Bentang Belia.

Supratno, Haris. 2016. Sosiologi

Novel Religi Sastra Indonesia.

Unesa University Press.

Sugiono. 2012. Metode Penelitian

Kuantitatif, Kualitatif, R\&D.

Bandung: Alfabeta.

Telfer, Elizabeth. 1996. Food for

Thought: Philosophy and Food.

London: Routledge. 